\title{
IDENTIDADE DE GÊNERO: ANOTAÇÕES SOBRE A MASCULINIDADE CONTEMPORÂNEA NA PUBLICIDADE
}




\section{IDENTIDADE DE GÊNERO: ANOTAÇÕES SOBRE A MASCULINIDADE CONTEMPORÂNEA NA PUBLICIDADE}

Resumo:

O presente trabalho analisa publicidades contemporâneas com o objetivo de observar a representação da masculinidade, especificamente, aspectos como a estética/sexualidade, a família e o trabalho, tendo em vista as mudanças que o padrão masculino hegemônico sofre nas últimas décadas. Fato estimulado pela intensificação do processo de globalização que levou a uma crise de identidades, entre elas a de gênero. Com isso, a publicidade torna-se uma das principais matrizes promotora de representações que servem como referência para que o homem contemporâneo (re)construa sua identidade de gênero.

Palavras chave: Identidade; Gênero Masculino; Publicidade

\section{IDENTIDAD DE GÉNERO: NOTAS DE LA MASCULINIDAD CONTEMPORÁNEA}

\section{EN LA PUBLICIDAD}

\section{Resúmen:}

El presente trabajo analiza publicidades contemporáneas con el objetivo de observar la representación de la masculinidad, específicamente, aspectos como la estética/sexualidad, la familia y el trabajo, teniendo en cuenta los cambios que la padronización del masculino hegemónico ha sufrido en las últimas décadas. Hecho estimulado por la intensificación del proceso de globalización que llevó a una crisis de identidades, entre ellas la del género. Con esto, la publicidad se torna una de las principales matrices promotora de representaciones que sirven como referencia para que el hombre contemporáneo reconstruya su identidad de género.

Palabras Clave: Identidad; Género Masculino; Publicidad

\section{GENDER IDENTITY: NOTES ABOUT CONTEMPORARY MASCULINITY IN PUBLICITY}

\section{Abstract:}

This paper examines contemporary publicity in order to observe the representation of masculinity, specifically, issues such as aesthetics / sexuality, the family and the work, in view of the changes that the hegemonic male pattern suffers in recent decades. Fact stimulated by the intensification of the globalization process that led to a crisis of identity, including the gender. Thus, publicity becomes a major matrices promoter of representations that serve as reference for the contemporary man (re)construct their gender identity.

Keywords: Identity; Gender Masculine; Publicity 


\section{INTRODUÇÃO}

Este trabalho propõe refletir a dinâmica dos valores masculinos - principais características associadas ao gênero masculino - que são responsáveis também pela formação da identidade dos sujeitos. Examinamos em alguns anúncios publicitários atuais como estes valores masculinos, afetados pelo processo de globalização e a crise da identidade de gênero masculino, são explorados pela publicidade, uma vez que essa se torna uma das principais fontes promotora de representações, entre elas as de masculinidade, nas sociedades atuais.

As publicidades destinadas ao público masculino apresentam-se como um fenômeno interessante para confirmar a tese de que embora o padrão tradicional de masculinidade sobreviva com nitidez atualmente, acaba também tendo muitas de suas características atualizadas pelas representações midiáticas. A publicidade se utiliza de valores circulantes na sociedade para elaborar seus discursos, sendo, portanto, por eles alimentada, da mesma forma que acaba contribuindo para a sistemática transformação da cultura e das identidades dos sujeitos contemporâneos.

No caso do gênero masculino (entendido aqui também como a masculinidade), reconhecemos sua amplitude e complexidade, principalmente, ao observá-lo como um verdadeiro processo de construção e não apenas como algo determinado pela questão biológica (SCOTT, 1995). Desse modo, está associado a um conjunto de características sociais e históricas que orientam o homem e, ao mesmo tempo, o diferenciam e o afastam do universo feminino.

Como forma de delimitar o que tratamos como gênero masculino daremos destaque a três categorias consideradas fundamentais, que compõem e reforçam a masculinidade -estética/sexualidade, família e trabalho -, para analisar suas representações no que se refere ao papel do homem através de anúncios publicitários. $\mathrm{E}$, assim, verificar como o modelo hegemônico masculino relacionado à heterossexualidade, aceito social e historicamente, se apresenta nas sociedades contemporaneidade.

É feito um breve apanhado de peças publicitárias impressas e veiculadas em revistas nacionais, duas delas claramente destinadas ao público masculino, Men's Helth e VIP, e a outra com expressiva inserção entre os homens, VEJA, que nos ajuda a entender a dinâmica da representação midiática relacionada ao gênero masculino. Foram escolhidos, aleatoriamente, oito anúncios publicitários levando em consideração apenas a destinação ao público masculino e a sua relação com as categorias teórico-analíticas apresentadas anteriormente, desconsiderando, portanto, o produto, seu uso ou seu valor de circulação no mercado. $O$ objetivo é realizar um exercício de análise sobre a representação do homem contemporâneo na publicidade, verificando possíveis atualizações naquele tido como o atual padrão hegemônico de masculinidade. 


\section{IDENTIDADES CONTEMPORÂNEAS}

Com o processo de consolidação da modernidade todo sujeito é visto como constituído por aspectos singulares e específicos que são responsáveis por sua identificação enquanto agente sociocultural. É esse conjunto de características, que está em contínuo processo de construção, que chamamos de identidade. Nesse sentido, Castells (1998) entende as identidades como fruto de significados e experiências de um povo ou indivíduo e que, portanto, devem ser observadas na relação com o contexto de sua formação e atuação.

A identidade é uma construção política e cultural gerada pelas relações sociais e simbólicas vividas cotidianamente pelos indivíduos (HALL, 2007). Nessa perspectiva, a identidade se configura como um produto que nunca se estabiliza e está continuamente em renovação, é resultado de todos os diálogos que o sujeito estabelece com os demais e das conexões heterogêneas com elementos culturais e sociais. Do ponto de vista sociológico, a construção da identidade perpassa diversos aspectos como o econômico, o étnico, o de gênero, o biológico, a memória coletiva, as indagações pessoais, entre tantos outros. Entretanto, "esses materiais são processados pelos indivíduos, grupos sociais e sociedades, que reorganizam esse significado em função de tendências sociais e projetos culturais enraizados em sua estrutura social, bem como em sua visão de tempo/espaço" (CASTELLS, 1998, p. 23).

Tendo em vista a gama de elementos que constituem as identidades é importante reconhecer que o indivíduo sempre propõe uma seleção daqueles que fazem sentido a sua subjetividade, pois é nesse jogo de escolhas que o sujeito se torna único, diferencia-se. Fato que vem ao encontro da discussão feita por Silva (2007) quanto à ideia de que toda identidade é marcada pela diferença, instituída invariavelmente em relação à(s) outra(s).

Contudo, as diferenças identitárias ressaltadas podem nos levar a pensar dois pontos divergentes e antagônicos relacionados à identidade: um "negativamente, por meio da exclusão ou da marginalização daquelas pessoas que são definidas como outros ou forasteiros"; outro, "como fonte de diversidade, heterogeneidade e hibridismo, sendo vista como enriquecedora" (HALL, 2003, p.34).

Como decorrência das transformações sociais e culturais trazidas pelo fenômeno da globalização, é assinalada uma constante fluidez identitária (BAUMAN, 2008), característica marcante nas identidades contemporâneas, isso principalmente pela ininterrupta necessidade de adaptação no tempo e no espaço. Sendo assim, não é possível discorrer sobre a identidade como algo dado e estanque, e sim como um processo em contínua formação. É o que afirma Woodward, "as identidades são diversas e cambiantes, tanto nos contextos sociais nos quais elas são vividas quanto nos sistemas simbólicos por meio dos quais damos sentidos a nossas próprias posições" (2007, p.33).

Bauman (2008) acrescenta à discussão a dificuldade de se definir as identidades contemporâneas, visto a liquidez que as constitui. Solidificar algo que 
tem como principal propriedade a liquidez seria, no mínimo, arriscado e alvo de críticas. Para o autor "as identidades ganharam livre curso, e agora cada indivíduo, homem ou mulher, pode capturá-las em pleno vôo, usando os seus próprios recursos e ferramentas" (idem, p. 35). Com isso, deixa-se de lado a noção de identidades pré-determinadas, por exemplo, pelas questões de classes ou pelo determinismo biológico, que embora sejam importantes e decisivas, não levavam em consideração a autonomia subjetiva de cada sujeito.

Nas sociedades atuais é preciso destacar o papel da mídia como responsável pelo grande fluxo de informação, fazendo com que seu grande alcance a torne uma das se não a principal fonte e mantenedora de padrões e tendências. Portanto, a mídia se apresenta como a grande matriz propulsora de diferentes tipos de identidades, sejam elas regionais, étnicas, de gênero, culturais, ou inúmeras outras que compõem os sujeitos. Para Ortiz "a mídia e as corporações se configuram em instâncias de socialização de uma determinada cultura (...) são agentes preferenciais na sua constituição, elas fornecem aos homens referencias culturais para suas identidades" (1996, p.145).

Muito em função disso as identidades passam a agregar como principal característica à questão do consumo, tipicamente associada à sociedade midiatizada do pós-guerra. Isso quer dizer que a mídia oferece um vasto repertório de escolhas, de bens matérias ou simbólicos, que ganham sentido pelo seu uso. Por isso é podemos observar a incessante inserção da publicidade em inúmeras, e cada vez mais inovadoras, plataformas midiáticas na nossa cotidianidade. Nesse contexto, o sujeito encontra um verdadeiro oásis de possibilidade de (re)inventar o tempo todo e em todo lugar suas identidades.

Para Giddens (2002) a busca por consumo de bens materiais e simbólicos, como matéria-prima para as identidades, ocorre em virtude do enfraquecimento das bases referenciais dos sujeitos, como a família e o Estado. Segundo Woodward (2007), seria a resposta a crise identitária, onde os sujeitos buscam, através de seus gostos pelo consumo de determinados produtos, subsídios que (re)criem suas identidades esvaecidas pela crise, produzindo, inclusive, novas identidades.

Nas sociedades atuais a construção da identidade é entendida como um processo contínuo que perpassa vários aspectos culturais e sociais de diversas origens e localidades. Por isso, consideramos a identidade como aquilo que nos narra enquanto sujeitos. O conjunto de nossa origem e cultura local, e dos elementos que caracterizam o tempo e espaço onde nos situamos e estabelecemos relações sociais e culturais.

\section{TRANSFORMAÇÃO SOCIAL DA MASCULINIDADE}

A chamada crise da modernidade, consequência da aceleração do processo de globalização no século passado, estimulado principalmente pela instauração 
do capitalismo como sistema econômico mundial, acarretou também outras crises como as das instituições sociais, do Estado e da família. Houve uma reconfiguração nas relações e padrões sociais e no modo como os sujeitos interagem com as esferas da sociedade. A crise abala e fragmenta as bases referenciais identitárias que sustentaram historicamente os sujeitos. Além disso, destacamos aqui, a de nosso interesse investigativo, a (suposta) crise na identidade de gênero masculino.

$\mathrm{Na}$ virada do século XX inicia gradualmente, em termos mundiais e expressivos, a aparição da figura feminina no espaço público. Nos anos de 1960, mais precisamente, com o surgimento de grupos feministas organizados, que lutavam pela igualdade de gênero e por políticas que protegessem e, de fato, integrassem as mulheres na vida pública, impulsionaram à transformação do papel feminino. O feminismo (e mais tarde, o movimento homossexual) ocupou-se também, ainda que indiretamente, do questionamento sobre o papel social do homem, produzindo efeitos sobre a reformulação do ideal masculino.

A instabilidade masculina, "resultante das transformações no comportamento das mulheres e na moral sexual, e do questionamento da posição dominadora e patriarcal dos homens na sociedade e na família" (LISBÔA, 1998, p. 131), gera uma série de mudanças no papel masculino e coloca em xeque o que até então se tinha como o ideal de masculinidade. Embora muito tratem enquanto crise da masculinidade, achamos prudente nos aproximar do pensamento de alguns autores, entre eles Oliveira (2004), que afirma que denominar essa movimentação de uma crise é uma forma de generalizar algumas insatisfações quanto ao exercício da masculinidade que estão relacionadas, principalmente, as classes dominantes. Para o autor, as classes populares ainda vivem intensamente a masculinidade tradicional (e hegemônica).

Entretanto, para autores como Nolasco "o desmoronamento do modelo machista [entendido como padrão hegemônico] é mais uma possibilidade do que uma perda" (1995, p.12), pois possibilita a flexibilidade e abertura para novas formas de masculinidade. Isso explica que apesar de o termo masculinidade ser usualmente empregado no singular, o que ocorre na verdade é a existência de inúmeras formas de masculinidades. Sendo assim, a "representação masculina associada a comportamentos de virilidade, posse, poder e atitudes agressivas se 'relativiza', abrindo frente a outras possibilidades de representação do homem" (idem, p. 19; grifo do autor).

O que ocorre é um mal-estar masculino nas sociedades contemporâneas. O sujeito não se reconhece mais por meio de um modelo hegemônico tradicional, nem mesmo por representações reconhecidas pelo imaginário social sobre o que é ser homem. Esse fato gera questionamento acerca do que vem a ser a masculinidade na contemporaneidade, considerando que surge "uma nãocoincidência do sujeito consigo mesmo e com as representações com as quais sua identidade foi construída" (ROSA, 2008, p.438).

A crescente desvinculação da sexualidade como ponto primordial da masculinidade nas últimas décadas talvez tenha sido o principal fator que desenca- 
deou a instabilidade masculina. Todas aquelas características conferidas ao sexo, que garantiam ao homem uma (quase) inquestionável posição social, foram desconstruídas e, para muitos, até mesmo rejeitadas. Logo, o homem contemporâneo reconhece que sua identidade está em mutação, e mais, que seus elementos formadores tornaram-se fugazes, considerando que as bases tradicionais de referência (o próprio sexo) e seus valores são continuamente reformulados.

Desse modo, a masculinidade que foi fundamentada histórica e tradicionalmente passou a ser questionada a partir da desestabilização trazida pelo desenvolvimento da categoria de gênero por femininas pós-estruturalistas. Para Scott (1995), o conceito de gênero foi criado para superar o determinismo biológico nas relações entre os sexos, envolvendo-os em um contexto social mais amplo e complexo. Embora, ainda seja evidente que a noção biológica de gênero continue existindo, há uma nítida relativização nas identidades de gênero dos sujeitos atuais. Entendemos a categoria gênero como elemento constituinte da identidade, um agregado de características particulares, construídas histórica e socialmente, com a função de identificar o comportamento e evidenciar as expectativas relacionadas ao que é ser homem ou mulher. Ressalta-se também que os referentes de gênero masculino e feminino têm sido sempre tratados com base na oposição entre os sexos, portanto, configurando-se como categorias relacionais, o que justifica todo o efeito trazido pelos Estudos Feministas no que se refere à masculinidade.

As características e os comportamentos que definem a masculinidade foram sendo definidos, ainda que submetidos aos valores de cada época, de forma precisa e reconhecida socialmente como parte da existência dos sujeitos a ela submetidos. Todo o conjunto de referência é desenvolvido sempre no sentido de afastar-se de tudo aquilo pertencente ao universo feminino. Por isso, conforme relata Nolasco (1995), a importância de o homem evitar a expressão dos sentimentos, viver quase que somente em espaços competitivos, de ser permanentemente provedor, e de se envolver em questões de trabalho e política e, por fim, de se apresentar sempre forte e capaz.

O gênero masculino é uma categoria que se configura como um repertório de identificações e comportamentos que servem de orientação para os homens (NOLASCO, 1995, p.25). Do mesmo modo, entende-se a masculinidade como uma norma social para o comportamento dos homens, ou seja, uma espécie de normatização que regula os seus papéis. Connel reitera que a masculinidade é "ao mesmo tempo a posição nas relações de gênero, nas práticas por as quais homens e mulheres se comprometem com essa posição de gênero, e os efeitos destas práticas na experiência corporal, na personalidade e na cultura" (1997, p. 6).

\section{MASCULINIDADE EM MUTAÇÃO? AS REPRESENTAÇÕES DO HOMEM NA PUBLICIDADE}


Aqui analisaremos de que modo questões como estética/sexualidade, família e trabalho relacionadas ao exercício da masculinidade vêm sendo representadas pela publicidade. O objetivo é observar as transformações ou a manutenção destas características, construídas e mantidas historicamente, para verificar de que forma a instabilidade da masculinidade contemporânea afetou o atual padrão hegemônico.

Trataremos, portanto, de conceituar tais aspectos discutindo-os a partir de exemplos de publicidades brasileiras impressas, veiculadas nas revistas, Men's Health, VIP e Veja, que retratem a conservação ou a flexibilidade das identificações e comportamentos do homem contemporâneo. Pois, como visto anteriormente, a instabilidade de instituições legitimadoras e a crescente participação das mulheres na vida pública impuseram uma reformulação na masculinidade. $O$ próprio homem reconhece a necessidade de adaptar-se a um novo cenário social e cultural, em que o padrão tradicional masculino encontra aceitação apenas parcial. Dessa forma, a publicidade se apresenta como uma importante promotora de novas (e também de tradicionais) formas de masculinidade.

O homem historicamente sempre esteve relacionado às questões de força, racionalidade e dominação, o que lhe afirmava superioridade em relação à mulher. Aspectos como afetividade e sentimentalismo deveriam ser rechaçados das atitudes masculinas, caso contrário poderiam colocar em xeque a masculinidade do sujeito (NOLASCO, 1995). Para compensar e até mesmo como forma de ocultar sua fragilidade, o gênero masculino é associado ao poder político, econômico e social, exercido em grande parte da história do mundo ocidental. O exercício de poder, que impôs a estrutura da maioria das sociedades ocidentais um ideal patriarcal em que a mulher foi submetida à vontade do homem, está muito mais vinculado a uma construção sócio-histórica, legitimada em grande parte por meio do discurso, do que propriamente pela força física.

A noção de poder e força masculina ainda são fortemente referendadas na publicidade, sendo atributos fundamentais à afirmação da masculinidade, principalmente, quando associada à submissão sexual da mulher. Ponto interessante é a remissão que alguns produtos, como carros, bebidas e tecnológicos, fazem ao universo masculino em anúncios publicitários com o intuito de reforçar o poder e a dominação.

Essa ideia é visualizada no anúncio da marca Ferracini' que traz a representação de submissão feminina ao homem. A disposição do homem em primeiro plano e o ângulo optado na fotografia favorece a figura masculina, reforçando sua superioridade. Aspectos como o controle da situação (poder) e a força masculina também são evidente na publicidade a partir, inclusive, do uso da força física sob a personagem feminina. A presença de um carro moderno, aparentemente potente, pode fazer alusão à potência sexual do sujeito masculino, uma vez que comumente o car-

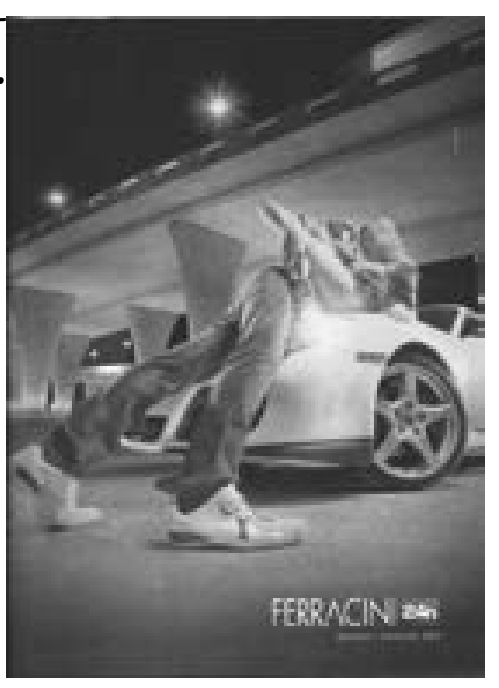
1 Anúncio impresso veiculado na página 51 da revista VIP de maio de 2011. 
ro é visto como elemento de reconhecimento social.

Publicidades de materiais esportivos, bebidas e de cuidado pessoal geralmente associam às qualidades dos produtos as características comumente reconhecidas como fundamentalmente masculinas. O uso de estratégia de aproximação com o público masculino como essa é devido à exigência cada vez maior por parte dos homens por produtos específico que atendam seus interesses, até décadas atrás ocultados, sem que isso gere desconforto ou remissiva ao universo feminino.

É exemplo o anúncio dos desodorantes da Garnier que explora a relação de complementaridade do produto - natural, durável e, até mesmo, rústico - com a figura do modelo negro viril, de torso definido e nu, complementado pela imagem das pedras (minerais vulcânicos) e do céu azul, remetendo a natureza. No caso deste anúncio, a analogia é feita através de elementos naturais com a imagem do personagem negro que historicamente é vinculado à virilidade e a máxima força masculina.

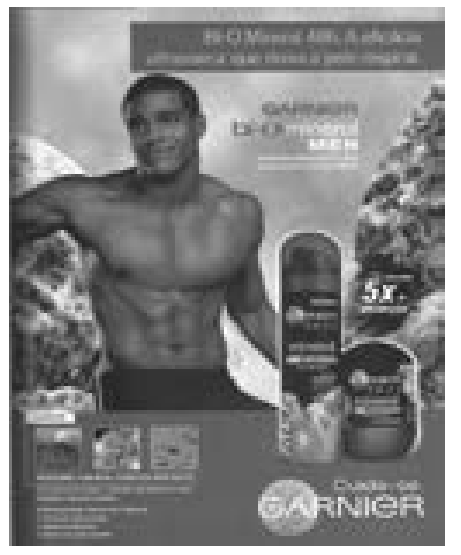

$\mathrm{Na}$ masculinidade percebemos uma relação de proximidade e complementaridade entre a estética e a sexualidade, pois um homem de boa aparência remete à virilidade e à saúde reprodutiva. A estética masculina, associada ao corpo perfeito e a traços másculos, que evidenciem força, autoridade e agressividade, está diretamente ligada ao papel sexual que o homem deve desempenhar; sempre pronto à atividade sexual. Sendo assim, a representação social da masculinidade passa necessariamente pela apresentação de um sujeito saudável, apto a exercer as atividades socialmente consideradas inerentes aos papéis sociais que lhe são atribuídos.

A sexualidade, de modo geral, se define em torno de conceitos sobre aspectos de personalidade, tendências comportamentais. Para Johnson configura-se como um conjunto de expectativas de comportamento que constituem o que denominamos de masculinidade e feminilidade (1997, p. 205). Ainda que não seja determinante, a sexualidade não pode ser ignorada como fator fundamental para a definição da identidade masculina. A centralidade no papel reprodutivo do homem impõe até hoje a associação à heterossexualidade e a um papel ativo, tanto na fase de conquista quanto no ato sexual em si.

No jogo das relações de gênero, o bem-vestir e a preocupação com a aparência são para muitos um auxílio à conquista, bem como resposta a exigência feminina, já que as mulheres passam a valorizar homens que se cuidam, sem perder sua masculinidade. Essa exigência é oriunda também da sociedade que se baseia em padrões representados pela mídia e os definem como ideais. Portanto, a definição do que na atualidade considera-se ideal estético masculino deve-se ao importante papel desempenhado pela mídia, especialmente, a publicidade. 


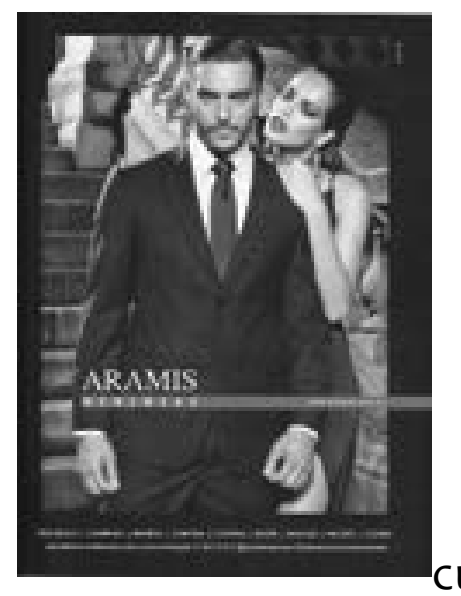

Nessa direção, a publicidade da grife Aramis² retoma a estética masculina valorizada e difundida pela mídia e, por conseguinte, pela sociedade. $\mathrm{O}$ anúncio retrata um homem de boa aparência, com traços viris e sérios (a barba e o olhar, por exemplo), características apreciadas historicamente e que são conexas a imagem de um sujeito contemporâneo, no que se refere postura elegante, ao cabelo cuidadosamente arrumado e as vestimentas alinhadas.

É importante retomar a noção de a estética masseu sentido mais amplo. No anúncio em questão percebe-se claramente o jogo de sedução e o interesse da mulher, observados na expressão facial, no posicionamento dos corpos e, também, na abertura da roupa da modelo, na conquista do homem. Isso evidencia que a boa aparência masculina é estimada pelo sexo oposto, tornando-se um facilitador para a conquista, bem como, incitação ao sexo.

O corpo perfeito é quase que um ideal de vida para muitos homens, que buscam manter a aparência jovial e saudável, pois um corpo definido denota virilidade e saúde, aspectos fundamentais no reforço à masculinidade heterossexual. Aqui, temos que reconhecer a interferência da mídia na construção de um discurso que reforça esses ideais, é o caso do anúncio da Davidoff Champion. A publicidade explora a estética (física), através do jogo de luzes e sombras, ressaltando a força e a virilidade masculina, representada pelos músculos de um corpo em boa forma. É curioso destacar a apropriação das atribuições da força masculina pelo produto, já que o frasco de perfume remete a um acessório de exercícios de musculação e, ainda, com expressiva referência fálica.

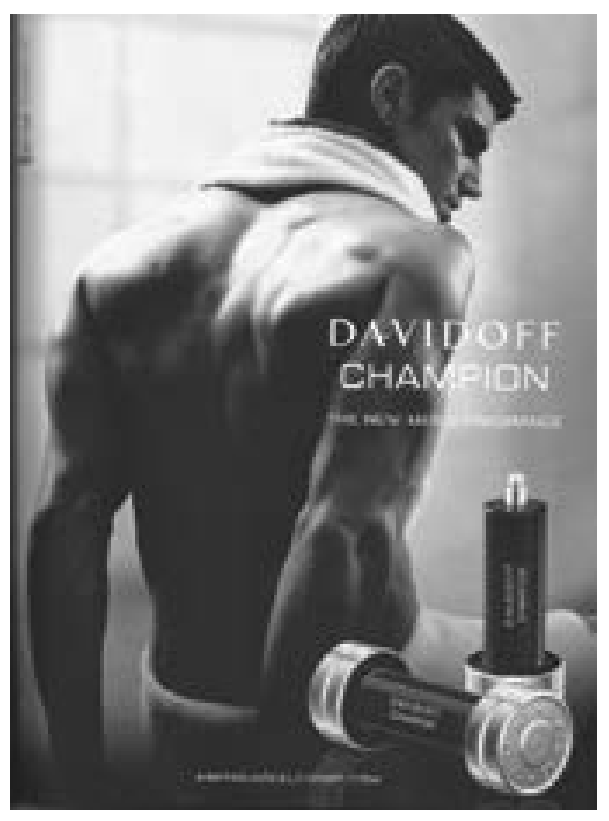

O papel de pai é uma função reiterada pelo ideal de masculinidade, inclusive como forma de afirmação identitária perante a sociedade, principalmente no que se refere a procriar e manter a espécie. A figura paterna é referência para os filhos, vista também como a responsável por impor limites e inserir seus descendentes socialmente. Assim, a paternidade é concebida como fundamental também pelo fato moral de poder sustentá-los e educá-los, já que essas são consideradas atribuições masculinas.

A representação do homem-pai nas publicidades analisadas mantém o caráter tradicional, com resquícios do patriarcalismo, reforçado pela representação da família segundo o modelo proposto historicamente pela Igreja Cató2Anúncio veiculado na página 23 da revista VIP de maio de 2011. 
lica. Essa questão vem ao encontro de que a constituição da família contribui para legitimar um padrão de masculinidade, em especial, por evidenciar a capacidade do homem de procriar e ser capaz de cuidar de esposa e filhos. Portanto, a formação familiar é decisiva ao homem, pois afasta as "dúvidas em relação ao noivo, quanto a uma possível orientação sexual pervertida" (OLIVEIRA, 2004, p.54) ou desorientação sexual.

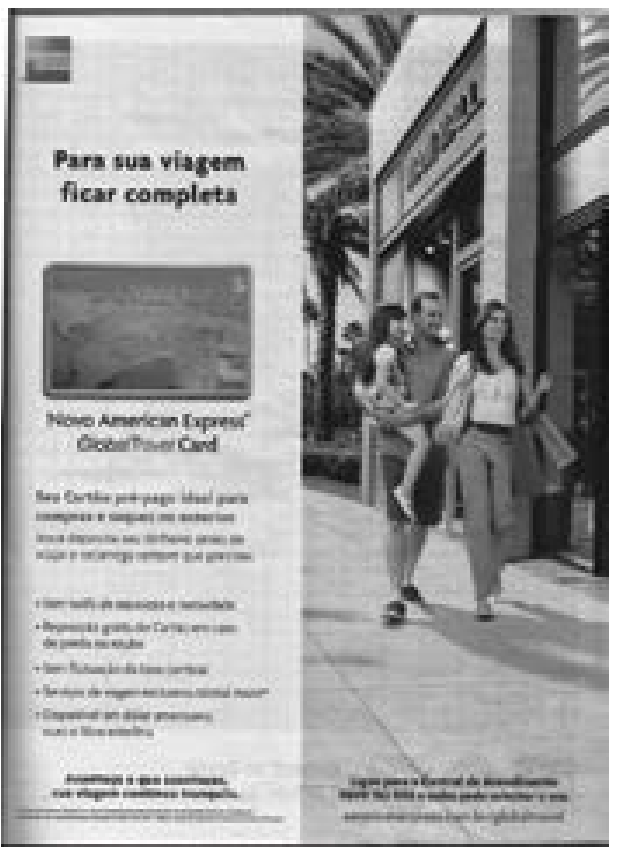

Ainda assim, os papéis de pai e esposo recebem maior abertura na atualidade. Percebe-se que o homem contemporâneo passa a interagir e se fazer mais presente no ambiente familiar, demonstrando maior atenção ao casamento e à educação dos filhos. É o que observamos no anúncio dos cartões de crédito American Express $^{3}$ em que há a representação da família tradicional - pai, mãe e filho. No anúncio identificamos algumas flexibilidades quanto à masculinidade e a família: o fato de o homem estar feliz acompanhando a esposa e cuidando da filha, num momento em que a mulher faz compras; a família reduzida de apenas um filho, característico das famílias atuais; e também, pode-se entender a ocasião como preocupação com o bem -estar e valorização da família, onde o homem se faz cada vez mais participativo.

A publicidade da CVC também exemplifica aspectos da figura paterna. Nela é representada a imagem de um (suposto) pai com seu filho em momento de lazer/férias, compreendido por a empresa anunciante ser uma agência de viagens. Destacamos duas prováveis ideias que em primeira vista retratam certa flexibilidade quanto ao padrão masculino tradicional. Uma diz respeito ao fato do pai estar mais próximo e atuante na educa-

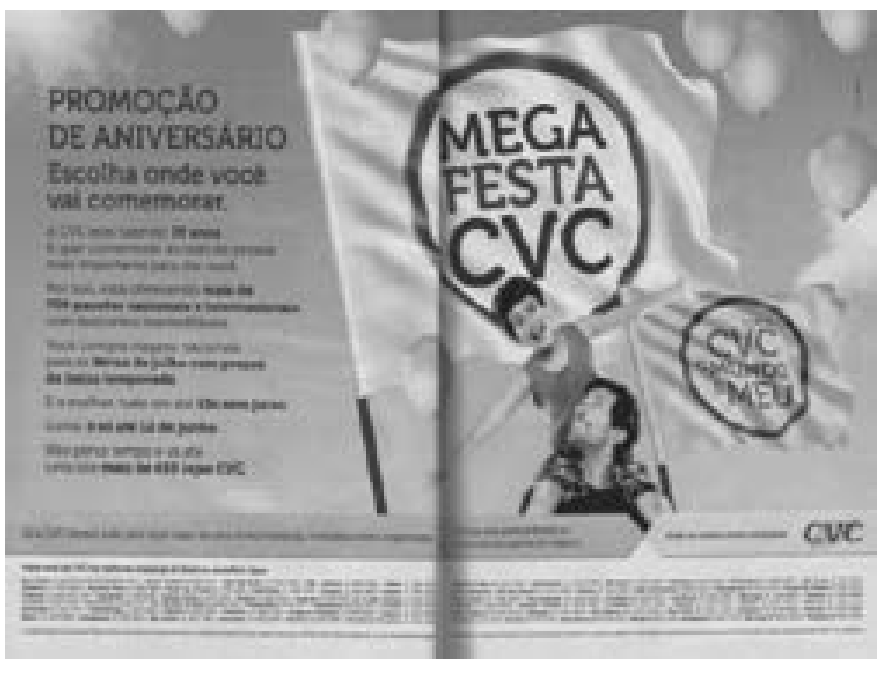
ção dos filhos. E, a outra, refere-se à ausência da figura feminina, no caso a materna, o que pode fazer alusão às novas formações familiares surgidas na contemporaneidade, incluindo, a de somente pai e filhos.

A categoria trabalho é outro ponto bastante caro a formação da masculinidade, devido à centralidade que o homem ainda ocupa na vida pública. Embora o homem continue desempenhando papel preponderante na produção 
sócio-econômica, cada vez mais perde espaço, ou pelo menos enfrenta relações de poder mais acirradas ante as mulheres. É a ideia de que nas sociedades atuais "o trabalho fora de casa deixa cada vez mais de ser uma responsabilidade preferencialmente masculina" (OLIVEIRA, 2004, p. 92). É provável que fatores como esse estimule uma maior preocupação com o próprio cuidado com a aparência, além do constante aprimoramento profissional, para que os homens se tornem mais competitivos no mercado de trabalho.

A ideia sobre o trabalho é comumente atrelada ao reconhecimento e ao sucesso profissional tão almejado pelo homem. A estabilidade profissional reflete um sujeito bem-sucedido, desejado pelas mulheres, que possui poder e é apto a circular por diferentes espaços da sociedade. Ser bem-sucedido e estável financeiramente, capaz de conforto e segurança à família, é decisivo para a masculinidade. Hoje essa questão se relativiza diante da necessidade de que as mulheres complementem a renda familiar através de sua inserção no mercado de trabalho.

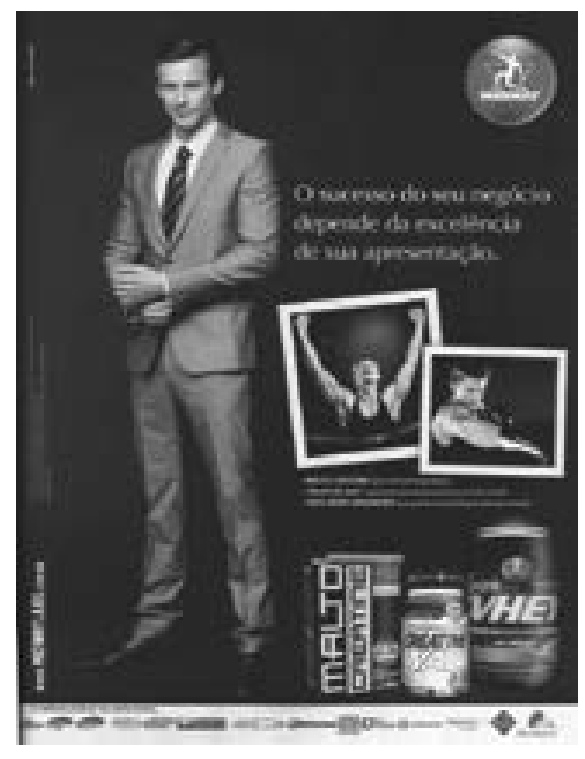

A publicidade do MidWay4, suplemento alimentar, representa um sujeito aparentemente bem-sucedido e de boa posição social, explicitado pelo traje (terno e gravata). O bom desempenho profissional é fundamental para a autoconfiança masculina, fato que é reiterado pela frase 0 sucesso de seu negócio depende da excelência de sua apresentação e, ainda, associa à importância do homem contemporâneo estar bem vestido e com boa aparência, como fator complementar ao sucesso profissional. A relação entre trabalho e a boa aparência/saúde é evidente no anúncio, quando traz à seriedade profissional a prática de exercícios físicos (boxe), ou seja, um caráter de complementaridade dado pelo discurso midiático.

A relação do homem com o trabalho é abordada também pelo informe publicitário do Gillette Mach3 Sensitive ${ }^{5}$. É interessante a associação entre o sucesso profissional e o cuidado com a aparência na chamada do informe $O$ sucesso está na sua cara, e ainda, reforçada pela frase Boa aparência é essencial para aumentar sua auto-estima e melhorar os relacionamentos pessoais e profissionais.

Portanto, além de habilidade técnicas de cada profissão, a preocupação com a aparência física é quase que uma exigência do mercado de trabalho, que passa a ser assimilada pelos homens, servindo de apoio para o desenvolvimento e êxito na carreira.

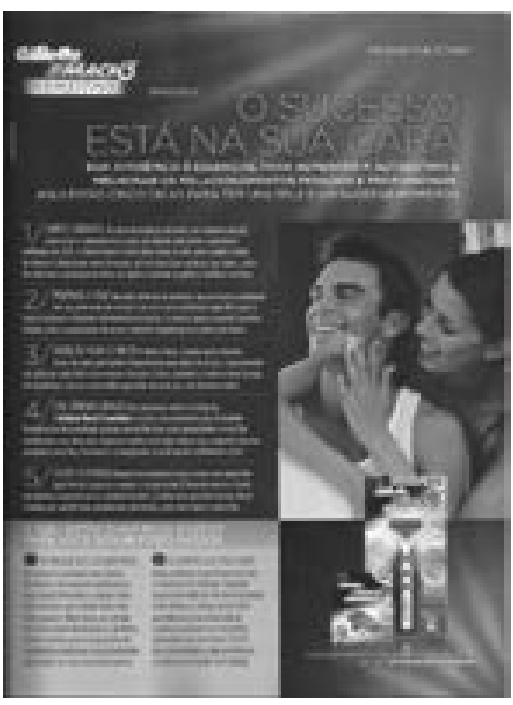
4Anúncio impresso veiculado na página 123 da revista VIP de maio de 2011. 5Anúncio impresso veiculado na página 64 da revista Men's Health de março de 2011. 
O que também pode trazer benefícios em outras relações sociais, como no relacionamento com as mulheres, fato que fica evidente na frase que justifica o cuidado com a barba e a pele, reiterado pela presença da figura feminina acariciando o rosto do modelo.

\section{CONSIDERAÇÕES}

Com este trabalho é possível visualizar, mesmo que de forma ainda inicial, a importância da publicidade no reforço de valores, na diminuição de preconceitos e naturalização do padrão hegemônico masculino que passa por mutações. Tornando-o, assim, uma referência significativa na formação identitária do homem contemporâneo.

Essas modificações trazem ao espaço público novas (e tradicionais) representações contribuindo à formação de um "novo" homem (BONÁCIO, 2009). Fato que reitera a noção de que as identidades, sejam de gênero ou não, estão sempre sob julgamento dos sujeitos e em adaptação conforme o tempo e o espaço em que são vividas. Nesse contexto, destaca-se o papel da publicidade, uma vez que essa ocupa expressiva posição entre as principais promotoras de representações e referências para a (re)construção das identidades, pois "na pós-modernidade, o sujeito se fragmenta e a cultura da mídia passa a ser o lugar de implosão da identidade" (GUILARDI-LUCENA, 2008, p.14).

Os homens retratados nos anúncios publicitários examinados neste artigo ratificam a questão de que o discurso midiático contribui para a estabilização de um novo perfil de masculinidade. Pois, atualiza e flexibiliza o padrão hegemônico que vigorou historicamente de forma bastante rígida. As características como estética/sexualidade, família e trabalho, ainda que tenham sofrido visíveis modificações no sentido de ser relativizadas, seguem fundamentais para a constituição da masculinidade, e consequentemente, da identidade.

O homem contemporâneo pelo viés da publicidade mostra-se menos rígido e mais maleável quanto a sua identidade de gênero, ainda que haja a manutenção de certos valores tradicionais da masculinidade. Não queremos aqui findar a discussão a respeito das adaptações relacionadas ao gênero masculino e, por conseqüência, da própria identidade deste sujeito que passa por profundas modificações. Pelo contrário, queremos suscitar novos debates acerca de como o modelo masculino hegemônico, que vigorou até poucas décadas, e ainda deixa resquícios de um homem conservador, em especial, naqueles assuntos que possam colocar em xeque a orientação sexual, se adapta em indivíduos cada vez mais preocupados com a aparência, o consumo, ao sucesso profissional e ao cuidado da parceira e dos filhos. 


\section{REFERÊNCIAS}

BONÁCIO, D. Discurso, mídia e identidade masculina: quem e esse "novo" homem. Dissertação (Mestrado em Letras). Universidade Estadual de Maringá - UEM, Maringá/PR, 2009. 160 páginas.

BAUMAN, Z. Identidade. Rio de Janeiro: Jorge Zahar Ed., 2005.

CASTELLS, M. O poder da identidade. A Era da Informação: economia, sociedade e cultura. 2ed. São Paulo: Paz e Terra, 1998.

CONNEL, R.W. La organización social de la masculinidad. In: VALDÉS, T.; OLAVARRÍA, J. Masculinidades. Chile: Ediciones de las mujeres, p. 1-25, n² 24, 1997. Disponível em:<http://www. pasa.cl/biblioteca. Acesso em: 10 nov. 2011.

GHILARDI-LUCENA, M.I. Representações sobre o gênero masculino na mídia impressa. In: Congresso da Associação Portuguesa de Ciências da Comunicação, $4^{\circ}$ SOPCOM, Aveiro, 2005. P. 1018-1025. Disponível em: http://www.bocc.uff.br/pag/ghilardi-maria-representacoes-genero-masculino-midia-imprensa-brasileira.pdf. Acesso em: 05 out. 2011.

GIDDENS, A. Modernidade e identidade. Rio de Janeiro: Jorge Zahar Ed., 2002.

HALL, S. A identidade cultural na pós-modernidade. Trad. Tomaz Tadeu da Silva e Guacira Lopes Louro. Rio de Janeiro: DP\&A, 2003.

. Quem precisa de identidade? In: SILVA, T. T. (org). Identidade e diferença. A pers-

pectiva dos Estudos Culturais. $7^{\text {a }}$ ed. Petrópolis: Vozes, 2007.

JABLONSKI, B. A difícil extinção do boçalossauro. In: NOLASCO, S.(org). A desconstrução do masculino. Rio de Janeiro: Rocco, 1995.

JOHNSON, A. Dicionário de sociologia: guia prático de linguagem sociológica. Rio de Janeiro, Jorge Zahar Ed, 1997.

LISBÔA, M. R. Masculinidade: as críticas ao modelo dominante e seus impasses. In: PEDRO, J.; GROSSI, M. (org). Masculino, feminino e plural. Florianópolis: Ed. Mulheres, 1998.

NOLASCO, S. A desconstrução do masculino. Rio de Janeiro: Rocco, 1995.

OLIVEIRA, P.P. A construção social da masculinidade. Belo Horizonte: Editora UFMG; Rio de Janeiro: IUFRJ, 2004.

ORTIZ, R. Mundialização e cultura. $2^{\text {a }}$ ed. São Paulo: Editora Brasiliense, 1996.

ROSA, M. Ser um homem segundo a tradição? In: Fractal. Jul/Dez 2008. Niterói. Disponível em: http://www.scielo.br/pdf/fractal/v2on2/10.pdf. Acesso em: 10 de setembro de 2010.

SCOTT, J. Gênero: uma categoria útil de análise histórica. Educação \& Realidade. Porto Alegre, vol. 20, n² 2,jul./dez. 1995, pp. 71-99.

SILVA, T. T. A produção social da identidade e da diferença. In: SILVA, Tomaz. Identidade e diferença. A perspectiva dos Estudos Culturais. $7^{a}$ ed. Petrópolis: Vozes, 2007.

WOODWARD, K. Identidade e diferença: uma introdução teórica e conceitual. In: SILVA, Tomaz. Identidade e diferença. A perspectiva dos Estudos Culturais. Petrópolis: Vozes, 2007. 


\section{Filipe Bordinhão dos Santos}

Mestrando pelo Programa de Pós-Graduação em Comunicação na Universidade Federal de Santa Maria e bolsista da Coordenação de Aperfeiçoamento de Pessoal de Nível Superior - CAPES. Bacharel em Comunicação Social - Publicidade e Propaganda pela UFSM (2010), onde é também acadêmico do Curso de Comunicação Social - Relações Públicas. Membro do grupo de pesquisa Mídia, recepção e consumo. 